\title{
Optimal Population Size and Urban-Rural Composition of a Distant, Large, Arid Island: A Model and Some Numerical Simulations
}

\author{
Amnon Levy ${ }^{*}, 1$ and Reza Zamani ${ }^{2}$ \\ ${ }^{1}$ School of Economics, University of Wollongong, New South Wales, Australia \\ ${ }^{2}$ School of Information Systems and Technology, University of Wollongong, New South Wales, Australia
}

\begin{abstract}
Low population density and large distance from civilization centers generate high costs of isolation. Immigration reduces these costs for veteran residents but reduces social and cultural cohesion, increases the demand for scarce resources and affects the rate of urban unemployment. An expected net benefit maximization model for determining the optimal population size and the equilibrium urban-rural composition of an island similar to Australia is constructed. The model is simulated for various agricultural water prices. The simulation results illustrate the central role of the effect of immigration on urban unemployment rate in the determination of the island's optimal population size.
\end{abstract}

\section{INTRODUCTION}

This paper deals with the optimal population size and rural-urban composition of a distant, large, arid island. The island's current population is small and has a low fertility rate. Distance and dispersion hinder communication and provision of commodities and services and the island's inhabitants bear mental and material costs of isolation. Immigration is the main way for increasing the island's population density, strengthening the island's international integration and, thereby, moderating the costs of isolation borne by the island's inhabitants. However, immigration reduces the island's levels of cultural and social cohesion. It also affects the island's rural and urban land and water use and natural environment.

Australia is an example of such an island. Its landmass is roughly the size of the United States without Alaska. Similar to the United States, it is endowed with attractive natural, social, political and economic amenities. However, its population is forty-five percent smaller than the ethnically diversified population of California - a frontier, largely arid place a hundred and fifty years ago that has been transformed to the United States' most populous, progressive and influential state and the world's fifth largest economy. As in the case of California, which had been isolated from the much more inhabited eastern coast of the United States by vast plains, desserts and rugged mountain ranges, and as in the late 1940s, 1950s and 1960s, a large immigration may have strong implications for Australia's isolation costs, ethnic composition, social cohesion, culture, education, stock of human capital, labor supply, domestic technology, domestic markets, industrial structure, environment, international affairs and global role.

Australia is the second driest continent $-\mathrm{a}$ condition that has given rise to Malthusian-type of sustainability arguments

\footnotetext{
*Address correspondence to this author at the School of Economics, University of Wollongong, New South Wales, Australia;

E-mail: levy@uow.edu.au
}

in support of small natural population growth and immigration quotas. It has been argued that Australia's fresh water supply is severely limited, its environment is fragile and its habitable land is roughly the size of France. Hence, while a small natural population growth is desirable, a strong population growth, which is attainable by large influx of immigrants, is environmentally and socially undesired $[1,2]$. In contrast, there have been claims that science and technology will provide a solution to Australia's current water shortages in the near future and will enable Australia to have a population of fifty million people and be a medium-size country by 2100 [3]. Immigration has been Australia's main source of population growth and this source has raised the Australian population's level of concentration in the urban centers and has had some positive economic and revitalizing impacts on these centers. In recent decades, however, immigration has generated significant internal migration of veteran residents from the country's major urban centers-Sydney and Melbourne - to less congested and more affordable coastal areas and regional cities. It has also led to emigration of skilful veteran Australians. There have been suggestions that as it is impossible to control the regional distribution of immigrants, a large environmental impact of the growing population on the major urban centers, Sydney in particular, should substantially reduce the immigration quotas [4]. In support of a position against population targeting, small or large, and in favor of market-based immigration policies, it has been argued that there is no strong theoretical linkage between economic prosperity and population size, that history does not provide much insight on the relation between welfare and population size, and that the costs of setting and pursuing population targets might exceed the possible benefits [5].

This paper argues that Australia's water shortage is not caused by population pressure, but is mainly due to inefficiency in the rural/urban allocation of water stemming from a large price differential. Hence, Australia's population may be allowed to grow considerably, even without scientific and technological changes (e.g., desalination and recycling) in the supply of water, by reducing the household-agricultural water-price differential and reforming the system of water 
rights. Although ninety-seven percent of Australia's human inhabitants are urban dwellers, about seventy percent of Australia's annual portable fresh water is used by the agricultural sector. Incompatible with the notion of comparative advantage, the production of some Australian agricultural goods are directly and indirectly subsidized and a large portion is exported. Moreover, in order to preserve water rights some upstream farmers hoard large quantities of water, much of which evaporates, whereas urban dwellers face restrictions on the purpose and mode of using water. A simple calculation reveals that, with the current average Australia household's water consumption, a forty-three percent reduction in the annual amount of water used by farmers may enable Australia to satisfy the household water needs of forty million people - a slightly larger population than that of California.

The objective of this paper is to develop a model for numerically simulating the possible effects of urban-rural water-price differential on the optimal population size and urban-rural composition of a distant, large, arid island similar to Australia. The building blocks of the model describe possible interrelationships between land, water, population, isolation, social cohesion, environmental damage and rural and urban dwellers' political power and expected benefits and costs. The model takes into account that population growth is generated through immigration, increases the demand for goods and the supply of labor and, consequently, affects the rate of unemployment. If the increase in the demand for urban labor generated by the rising aggregate demand for goods is larger (smaller) than the increase in the urban labor supply, the rate of urban unemployment diminishes (increases) with population growth. The equilibrium urbanrural composition is defined and incorporated into an expected net benefit maximization problem that generates the island's optimal population size. The simulation technique and the choice of the model parameter values are explained. The simulation results of the effect of the urban-rural water price differential on the optimal population size and ruralurban composition are generated under alternative assumptions about the relationship between urban unemployment and population growth.

\section{LAND, WATER AND POPULATION: CONSTRAINTS, COSTS AND INCOMES}

The island's land fit for tillage and habitation is $\hat{L}$ acres. The island's population is $N$. The average personal residential area is $l$ acres. Hence, the island's arable land, $L_{r}$, is:

$L_{r}=\hat{L}-l N$

The island's land and its surrounding atmosphere are degraded by urban and farming activities. The island's government sets land-environmental rates for urban households and farmers and invests the revenues collected in rehabilitating the island's land and environment.

The island's annual sustainable volume of water available and suitable directly and indirectly (through agricultural goods) for human consumption is $\hat{W}$ cubic meters. The average annual personal household water-consumption is $w$ cubic meters. Hence, the annual amount of water available for farming, $W_{r}$, is:

$W_{r}=\hat{W}-w N$

The government supplies waters, sets water rates for users and invests the revenues collected in transporting fresh water and in treating and disposing effluents.

The island's workers are equally competent. They and their dependents are divided into $N_{r}$ rural dwellers and $N_{u}$ urban dwellers:

$N_{r}+N_{u}=N$

The island faces an infinitely elastic supply of equally competent immigrant workers and their dependents, but its population cannot exceed the island's carrying capacity $\left(N_{\max }\right)$ :

$N \leq N_{\max }=\min \{(\hat{L} / l),(\hat{W} / w)\}$

In the case of a large but arid island, such as Australia, the carrying capacity is determined by water availability, $N_{\max }=\hat{W} / w$

The inhabitants of the island bear mental and material costs of isolation. Their personal isolation costs decline with the size of the local urban and rural communities from a peak of $\hat{c}_{u}^{I}$ for an urban dweller and a peak of $\hat{c}_{r}^{I}$ for a rural dweller. In particular, the isolation cost for an urban dweller is assumed to be given by:

$$
c_{u}^{I}=\frac{\hat{c}_{u}^{I}}{N_{u}+\delta_{u} N_{r}}=\frac{\hat{c}_{u}^{I}}{\delta_{u} N+\left(1-\delta_{u}\right) N_{u}}
$$

where $0<\delta_{u} \leq 1$ and indicates that an increase in the number of farmers might have a smaller moderating effect on an urban dweller's isolation cost than an identical increase in the number of urban dwellers. Similarly, the isolation cost for a farmer is given by:

$c_{r}^{I}=\frac{\hat{c}_{r}^{I}}{N_{r}+\delta_{r} N_{u}}=\frac{\hat{c}_{r}^{I}}{N-\left(1-\delta_{r}\right) N_{u}}$

where $0<\delta_{r} \leq 1$ and indicates that an increase in the number of urban dwellers might have a smaller moderating effect on a rural dweller's isolation cost than an identical increase in the number of members in his own sector.

The island's fertility rate is negligible (relative to the land mass) and its population growth depends entirely on immigration. Immigrants are culturally and socially different from veteran islanders. Hence, while the costs of isolation decrease with the size of the island's population, the cumulative costs of loss of cultural cohesion and social harmony rise. The loss of cultural and national cohesion and social harmony for an urban dweller is given by:

$c_{u}^{S}=\mu_{u} N^{\eta_{u}}, \quad \mu_{u}>0,0<\eta_{u} \leq 1$

and for a rural dweller by: 
$c_{r}^{S}=\mu_{r} N^{\eta_{r}}, \mu_{r}>0,0<\eta_{r} \leq 1$

Urban dwellers and rural dwellers might also incur political costs, or benefits, in accordance with their sector's relative bargaining power. These political costs (benefits) take the form of low (high) level of public investment in infrastructure (i.e., schools, utilities and transportation and communication systems). Assuming that a sector's bargaining power depends upon its population share vis-à-vis its counterpart's population share and recalling the populationcomposition equation, the political costs (benefits) for an urban dweller are given by:

$c_{u}^{P}=\psi_{u}\left[\left(N_{r}-N_{u}\right) / N\right]=2 \psi_{u}\left[0.5-\left(N_{u} / N\right)\right], \psi_{u} \geq 0$

and for a rural dweller by:

$c_{r}^{P}=\psi_{r}\left[\left(N_{u}-N_{r}\right) / N\right]=2 \psi_{r}\left[0.5-\left(N_{r} / N\right)\right], \psi_{r} \geq 0$.

A proportion $0<\gamma_{u}<1$ of the urban population belongs to the urban labor force. Correspondingly, the number of dependents per urban worker is $1 / \gamma_{u}-1$. Each urban worker has a potential income, $y_{u}$ (a positive scalar), and a probability of being employed that may depend on the island's population size, $0<\phi(N)<1$. Consequently, his, or her, expected income is $\phi(N) y_{u}$. The sign of $d \phi / d N$ is positive, zero, or negative if the number of new urban jobs created by the increased aggregate demand for goods is larger than, equal to, or smaller than, the increase in the labor supply generated by population growth (i.e., admission of immigrants). In the case where the number of new urban jobs created by the increased aggregate demand for goods is smaller than the increase in the labor supply generated by the island's population growth, the probability of being employed for an urban dweller is assumed to be given by:

$\phi(N)=1-\varphi \frac{N}{N_{\max }}, 0<\varphi \leq 1$

In the case where the number of new urban jobs generated by the increased aggregate demand for goods is larger than the increase in the labor supply generated by the island's population growth, the probability of being employed for an urban dweller is taken to be given by:

$\phi(N)=1-\tilde{\varphi} \frac{N_{\max }}{N}, 0<\tilde{\varphi} \leq \frac{N}{N_{\max }}$

A proportion $0<\gamma_{r}<1$ of the rural population constitutes the rural labor force and taken to be self-employed farmers. The number of dependents per farmer is $1 / \gamma_{r}-1$. The arable land and the amount of water unused by households are fully used by farmers. All the farmers are endowed with equal land and water allotments and use an identical technology represented by a Cobb-Douglas production function. That is, each farmer's potential annual output is given by $A_{r}\left(L_{r} / \gamma_{r} N_{r}\right)^{\alpha}\left(W_{r} / \gamma_{r} N_{r}\right)^{\beta}$, where $A_{r}>0$ and $0<\alpha, \beta<1$ indicate the technological shift parameter and production elasticities with respect to land and water, respec- tively. Every farmer faces a probability $0<1-\theta<1$ of production failure due to natural causes and receives an exogenously given price, $P$, on the composite agricultural good. Consequently, and in recalling the land, water and population equations, each farmer's expected revenue is given by:

$$
\begin{aligned}
& y_{r}=\theta P A_{r}\left[(\hat{L}-l N) / \gamma_{r}\left(N-N_{u}\right)\right]^{\alpha} \\
& \times\left[(\hat{W}-w N) / \gamma_{r}\left(N-N_{u}\right)\right]^{\beta} \\
& =\theta P A_{r}(\hat{L}-l N)^{\alpha} \times(\hat{W}-w N)^{\beta} \\
& /\left[\gamma_{r}\left(N-N_{u}\right)\right]^{\alpha+\beta} .
\end{aligned}
$$

As mentioned earlier, the island's government sets water and environmental rates and invests the revenues collected in transporting fresh water to consumers, treating and disposing effluents and rehabilitating the island's environment. Having $1 / \gamma_{u}-1$ dependents, each consuming $w$ cubic meters of water per annum, the annual water bill for any urban worker is:

$c_{u}^{W}=w q_{u} / \gamma_{u}$

where $q_{u}$ is the urban water rate that includes charges for supply-system service and for treating and disposing effluents. Having $1 / \gamma_{r}-1$ dependents and a farm, the annual water bill for a farmer is:

$$
\begin{aligned}
& c_{r}^{W}=\left[w / \gamma_{r}+(\hat{W}-w N) / \gamma_{r} N_{r}\right] q_{r} \\
& =\left[w / \gamma_{r}+(\hat{W}-w N) / \gamma_{r}\left(N-N_{u}\right)\right] q_{r}
\end{aligned}
$$

where $q_{r}$ is the rural water rate that includes charges for supply-system service and for treating and disposing effluents.

The sum of the annual environmental bills of the urban workers and farmers is equal to the cost of the full rehabilitation of the annual degradation of the island's land and the atmosphere above it. The cost of rehabilitating the annual environmental degradation caused by an urban worker and his, or her, dependents is proportional to their dwelling area:

$c_{u}^{E}=e_{u}\left(l / \gamma_{u}\right)$

where $e_{u}$ is the annual environmental rehabilitation cost per acre of urban land. The cost of rehabilitating the annual environmental degradation caused by a farmer and his, or her, dependents is proportional to the sum of their dwelling and farming areas:

$$
\begin{aligned}
& c_{r}^{E}=e_{r}\left[l / \gamma_{r}+(\hat{L}-l N) / \gamma_{r} N_{r}\right] \\
& =e_{r}\left[l / \gamma_{r}+(\hat{L}-l N) / \gamma_{r}\left(N-N_{u}\right)\right]
\end{aligned}
$$

where $e_{r}$ is the annual environmental rehabilitation cost per acre of rural land.

In addition, the island's residents pay the government annual rents for having property rights on their dwelling land and the buildings on the land. The property rents finance the government's activities, excluding the already considered costs of supplying water, treating and disposing effluents and rehabilitating the island's environment. In response to supply 
and demand conditions, the annual property rent increases with concentration - the sector's population share. For an urban worker this rent is:

$c_{u}^{L}=\left[\tau_{u}\left(N_{u} / N\right)\right]\left(l / \gamma_{u}\right)$

and for a farmer it is:

$c_{r}^{L}=\left[\tau_{r}\left(N_{r} / N\right)\right]\left[l / \gamma_{r}+(\hat{L}-l N) / \gamma_{r} N_{r}\right]$

where $\tau_{r}$ and $\tau_{u}$ are positive scalars that represent the upper-bound on the property rent per urban acre (i.e., when $\left.N_{u} \rightarrow N\right)$ and the upper-bound on the property rent per rural acre (i.e., when $N_{r} \rightarrow N$ ), respectively, and where $l / \gamma_{u}$ and $l / \gamma_{r}+(\hat{L}-l N) / \gamma_{r} N_{r}$ indicate the average number of acres occupied by an urban worker and a farmer and their dependents, respectively.

RURAL-URBAN EQUILIBRIUM AND THE OPTIMAL POPULATION SIZE

In view of the above assumptions and specifications, the expected net benefit for every urban worker and his, or her, dependents is:

$$
\begin{aligned}
& v_{u} \equiv \phi(N) y_{u}-\left(c_{u}^{I}+c_{u}^{S}+c_{u}^{P}\right) / \gamma_{u} \\
& -c_{u}^{W}-c_{u}^{E}-c_{u}^{L} \\
& =\phi(N) y_{u}-\left\{\frac{\hat{c}_{u}^{I}}{\delta_{u} N+\left(1-\delta_{u}\right) N_{u}}\right. \\
& +\mu_{u} N^{\eta_{u}}+\psi_{u}\left[1-2\left(N_{u} / N\right)\right] \\
& \left.+w q_{u}+\left(e_{u}+\tau_{u} \frac{N_{u}}{N}\right) l\right\} / \gamma_{u}
\end{aligned}
$$

and the expected net benefit for every farmer and his, or her, dependents is:

$$
\begin{aligned}
& v_{r} \equiv y_{r}-\left(c_{r}^{I}+c_{r}^{S}+c_{r}^{P}\right) / \gamma_{r} \\
& -c_{r}^{W}-c_{r}^{E}-c_{r}^{L} \\
& =\theta P A_{r}(\hat{L}-l N)^{\alpha}(\hat{W}-w N)^{\beta} \\
& /\left[\gamma_{r}\left(N-N_{u}\right)\right]^{\alpha+\beta} \\
& -\left\{\frac{\hat{c}_{r}^{I}}{N-\left(1-\delta_{r}\right) N_{u}}+\mu_{r} N^{\eta_{r}}\right. \\
& \left.+\psi_{r}\left[1-2\left(N_{r} / N\right)\right]\right\} / \gamma_{r} \\
& -\left[w / \gamma_{r}+(\hat{W}-w N) / \gamma_{r}\left(N-N_{u}\right)\right] q_{r} \\
& -\left[l / \gamma_{r}+(\hat{L}-l N) / \gamma_{r} N_{r}\right] \\
& \times\left[e_{r}+\tau_{r}\left(N_{r} / N\right)\right] .
\end{aligned}
$$

A rural-to-urban net migration reflects an adjustment process that exhausts any arbitrage (Schultz JPE 1962, Sjaastad JPE 1962, Todaro AER 1969) [6-8]. That is, $\dot{N}_{u}(t)=\pi\left[v_{u}(t)-v_{r}(t)\right]$, where $\pi>0$ denotes the speed of adjustment. As the analysis is concerned with the island's optimal population and decomposition by sector, the case where the island's inhabitants are allowed to enter and exit each sector without delay at any instance is taken into account (i.e., completely open access, $\pi \rightarrow \infty$ ). Consequently, and recalling the assumption that all workers are equally competent, the island's urban-rural structure is in equilibrium with $v_{u}(t)=v_{r}(t)$ at every instance, assuming that the transfer costs are negligible. Consequently, the island's equilibrium urban-population, $N_{u}^{*}$, satisfies:

$$
\begin{aligned}
& \phi(N) y_{u}-\left\{\frac{\hat{c}_{u}^{I}}{\delta_{u} N+\left(1-\delta_{u}\right) N_{u}^{*}}\right. \\
& +\mu_{u} N^{\eta_{u}}+\psi_{u}\left[1-2\left(N_{u}^{*} / N\right)\right] \\
& \left.+w q_{u}+\left(e_{u}+\tau_{u} \frac{N_{u}^{*}}{N}\right) l\right\} / \gamma_{u} \\
& v_{r} \equiv y_{r}-\left(c_{r}^{I}+c_{r}^{S}+c_{r}^{P}\right) / \gamma_{r} \\
& -c_{r}^{W}-c_{r}^{E}-c_{r}^{L} \\
& \quad=\theta P A_{r}(\hat{L}-l N)^{\alpha}(\hat{W}-w N)^{\beta} \\
& /\left[\gamma_{r}\left(N-N_{u}\right)\right]^{\alpha+\beta} \\
& -\left\{\frac{\hat{c}_{r}^{I}}{N-\left(1-\delta_{r}\right) N_{u}}+\mu_{r} N^{\eta_{r}}\right. \\
& \left.+\psi_{r}\left[1-2\left(N_{r} / N\right)\right]\right\} / \gamma_{r} \\
& -\left[w / \gamma_{r}+(\hat{W}-w N) / \gamma_{r}\left(N-N_{u}\right)\right] q_{r} \\
& -\left[l / \gamma_{r}+(\hat{L}-l N) / \gamma_{r} N_{r}\right] \\
& \times\left[e_{r}+\tau_{r}\left(N_{r} / N\right)\right] .
\end{aligned}
$$

Similar to the consideration of per capita income in economic growth studies, per capita expected net benefit, $\left(\gamma_{u} N_{u} v_{u}+\gamma_{r} N_{r} v_{r}\right) / N$, indicates the expected net benefit for the representative islander-an imaginary urban-rural hybrid. The population size that maximizes $\left(\gamma_{u} N_{u} v_{u}+\gamma_{r} N_{r} v_{r}\right) / N$, while an urban-rural equilibrium is maintained, is the island's optimal population size. Denoting the model's parameter set as $X$ and the rural-urban combination that satisfies the equilibrium condition $v_{u}=v_{r}$ as $N_{r}^{*}$ and $N_{u}^{*}$, and noting that $v_{u}\left(N, N_{u}^{*}, X\right)$ and $v_{r}\left(N, N_{u}^{*}, X\right)$ are explicitly obtained by substituting $N_{u}^{*}$ into the expected net benefit equations, the island's optimal population size is $\arg \max \left\{\left[N_{u}^{*} v_{u}\left(N, N_{u}^{*}, X\right)-N_{r}^{*} v_{r}\left(N, N_{u}^{*}, X\right)\right] / N\right\}$.

If $d^{2} v / d N^{2}<0$, there exists an interior solution, $N^{o}$, satisfying:

$$
\begin{aligned}
& v_{u}\left(N^{o}, N_{u}^{*}, X\right) \frac{d N_{u}^{*}}{d N}+N_{u}^{*} \frac{d v_{u}\left(N^{o}, N_{u}^{*}, X\right)}{d N} \\
& =v_{r}\left(N^{o}, N_{u}^{*}, X\right) \frac{d N_{r}^{*}}{d N}+N_{r}^{*} \frac{d v_{r}\left(N^{o}, N_{u}^{*}, X\right)}{d N} .
\end{aligned}
$$

As there is not a close-form solution, the optimal population size and its equilibrium rural-urban composition are found through numerical simulations with heuristic assumptions about the values of the model parameters. 


\section{SIMULATION'S TECHNIQUE AND PARAMETERS}

The simulation program uses the Lagrange method and incorporates the sectors' equilibrium condition into the objective function in a quadratic manner, $\left(\gamma_{u} N_{u} v_{u}+\gamma_{r} N_{r} v_{r}\right) / N-\lambda\left(v_{u}-v_{r}\right)^{2}$, where $\lambda$ denotes the Lagrange multiplier and measures the shadow value of an urban-rural arbitrage for the representative islander. The simulation program has been written in $\mathrm{C}^{++}$programming language under Microsoft Windows operating system. With meaningful intervals, all possible numerical combinations of $N$ and $N_{u}$ values are used to create a grid in which the first dimension represents $N$ and the second dimension $N_{u}$. A surface $\left(\gamma_{u} N_{u}^{\prime} v_{u}+\gamma_{r} N_{r}^{\prime} v_{r}\right) / N^{\prime}-\lambda\left(v_{u}^{\prime}-v_{r}^{\prime}\right)^{2}$ is projected on the grid with $N^{\prime}$ and $N_{u}^{\prime}$ revealing the values of the first and second dimensions, respectively. The combination associated with the highest peak in this surface is selected as the solution.

The simulations are performed with predetermined values of some of the parameters and calibrated values of the rest of the parameters that replicate the 2004/5 size and urban-rural composition of Australia's population with the proposed model as the expected personal net benefit maximizing size and the equilibrium composition. The calibration of the model's parameters is based on the following assumptions.

The potential income of each urban worker $\left(y_{u}\right)$ is 65,000 dollars and the probability of being employed $(\phi)$ is 0.95 . Each urban worker, female or male, has a sole responsibility for 1.5 dependents and, correspondingly, $\gamma_{u}=0.4$.

The female and male heads of the farmstead constitute a combined rural unit that generates the revenues, pays the costs and has responsibility for three dependents (i.e., $\left.\gamma_{r}=0.25\right)$. Every farm faces a probability of 0.333 of production failure (i.e., $\theta=0.667$ ).

Based on an average of sampled Australian urban household's water bills, there was a charge of 0.98 dollar per cubic meter of fresh water used and a charge of 1.09 dollars on water service and sewerage service per cubic meter. Hence, $q_{u}$ is set to be 2.07 dollars. Based on information obtained on water costs from interviewing farmers in New South Wales, $q_{r}$ is set to be 0.07 dollar.

Based on a sample average of Australian urban household's water consumption, the average annual household water-consumption $(w)$ is 120 cubic meters per person. Multiplying this figure by the 2004/5 population of Australia $(20,000,000)$ and by the inverse of the current urban sector's water consumption in Australia (1/0.3) we approximate the annual sustainable volume of water suitable for urban and rural consumption $(\hat{W})$ to be $8,000,000,000$ kiloliters. We assume that water is the binding constraint and therefore: $N_{\max }=\hat{W} / w=66,666,667$.

We make a conservative assumption that only ten percent of Australia's landmass-768,200 squared kilometers-is habitable. Equivalently, $\hat{L}=192,050,000$ acres. We assume that a hundred squared meters, including an equal share in public areas, is the residential area per person, which is translated to $l=0.05$ acre.

We set $\delta_{u}, \delta_{r}, \eta_{u}, \eta_{r}, \alpha$ and $\beta$ to be equal to their assumed mid-range value, 0.5 . Consistently with unbiased public planning, we set $\psi_{u}=\psi_{r}=0$ to eliminate populist reaction to sector-based political bargaining power.

Using the above values, the calibrated parameter values obtained by simulating the 2004/5 population size and urban composition and with some additional assumptions are as follows.

The annual environmental rehabilitation cost per acre of urban land $\left(e_{u}\right)$ is 5,000 dollars - equivalent to 0.5 percent loss of value per urban acre whose current market value is $1,000,000$ dollars. Assuming that urban land and the atmosphere above it are much more intensively used, the environmental damage per acre inflicted by farmers is much less, $e_{r}=65$ dollars.

It is assumed that due to isolation the average urban Australian travels abroad for non-business related reasons once every 2.5 years for a period of 30 days and his, or her, overall costs are 4,250 dollars including 2,000 dollars for airfare and 2,250 dollars for accommodation, meals and transportation. This amount implies that the current isolation cost for a representative urban dweller is 1,900 dollars per annum. Recalling urban isolation cost equation, $\hat{c}_{u}^{I}=1900\left(N_{u}+\delta_{u} N_{r}\right)$. Given that the population of Australia is $20,000,000$ and is 97 percent urban, $N_{u}=19,200,000$ and $N_{r}=800,000$. Recalling that $\delta_{u}=0.5$,

$\hat{c}_{u}^{I}=1,900(19,200,000+0.5 \times 800,000)=33,320,000,000$

dollars. We assign identical value to $\hat{c}_{r}^{I}$.

We assume that the current annual value of the loss of cultural and national cohesion and social harmony is 2,000 dollars-about five percent of the per capita income-for any urban dweller. Recalling the cultural cohesion and social harmony loss function for urban dwellers and considering a population is $20,0000,000$ and $\eta_{u}=0.5$, then $\mu_{u}=2,000 / \sqrt{20,000,000}=0.4472$. In view of the higher percentage of support for conservative parties in rural Australia, it is assumed that the current annual value of the loss of cultural and national cohesion and social harmony for a rural dweller is twice the loss for urban dweller $-4,000$ dollars. Recalling that $\eta_{r}=0.5$, $\mu_{r}=4,000 / \sqrt{20,000,000}=0.8944$.

A $P A_{r}=33$ dollar was obtained by substituting into the farmer's expected revenue function the chosen values of $\alpha$, $\beta \theta, \gamma_{r}, \hat{L}$, and $\hat{W}$, the 2004/5 figures of $N=20,000,000$ and $N_{u}=19,400,000$, and the revenue of $y_{r}=164,000$ dollars that is twice the average Australian 
farm's income in 2001-02 in 2004/5 prices (Table S1, Selected socio-economic measures, Australian Bureau of Agricultural and Resource Economics, Australian Government).

From the urban rent equation, $\tau_{u}=c_{u}^{L} /\left[\left(l / \gamma_{u}\right)\left(N_{u} / N\right)\right]$. Recalling that $\gamma_{u}=0.4$, each urban worker has 1.5 dependents and hence providing accommodation for 2.5 people - half an average family. The average weekly rental cost of urban accommodation for half a family is 206.5 dollars per week, which implies that $c_{u}^{L}=206.5 \times 52=10,738$ dollars per annum. Recalling further that $N_{u} / N=0.97$ and that $l=0.05$, then $\tau_{u}=88,560$ dollars. A $\tau_{r}=500$ dollars is consistent with an average return (net of the costs on other hired, or purchased, inputs and self labor) of 500 dollars per annum on an acre of arable land.

\section{EMPLOYMENT PROSPECTS AND SIMULATION RESULTS}

The simulations of the effects of the urban-rural waterprice differential on the optimal population and urban-rural composition of an island similar to Australia are conducted for three scenarios:

A. the probability of urban employment is not affected by the size of the urban population and is equal to the $2004 / 5$ one $(\phi=0.95)$;

B. the probability of urban employment increases with the size of the urban population with

$\tilde{\varphi}=\frac{1-\phi(N)}{N_{\max } / N}=\frac{0.05}{66.666 / 20}=0.015 ;$ and

C. the probability of urban employment decreases with the size of the urban population with

$\varphi=\frac{1-\phi(N)}{N / N_{\max }}=\frac{0.05}{20 / 66.666}=0.165$.

In each scenario, the simulations are conducted with the assumption that the full price of urban water is fixed and equal to 2.07 dollar per cubic meter regardless of changes in the population size and in the agricultural water consumption induced by the changes in the agricultural water price. This assumption suggests, for tractability, a balance, following an increase in the agricultural water price, between the upward pressure on urban water price generated by the growing urban population and the downward pressure on urban water price stemming from the decline in the agricultural water consumption. The simulation results are summarized in Table 1. They illustrate the central role of the effect of immigration on the prospects of urban employment in determining the island's optimal population size. As long as the probability of urban employment is not diminished by population growth (i.e., scenarios A and B), lowering the urban-rural water price discrepancy from the current level of two dollars will largely increase, albeit in diminishing numbers, the island's population without a loss of expected net benefit for urban dwellers and farmers. A rise of about seventy-three cents, in scenario A, or of a mere twenty-three cents, in scenario $B$, of the agricultural water price may facilitate the doubling of the population of a large island like Australia and reaching a medium-size international rank through immigration without compromising the current prospects of employment and net benefits (including environmental ones) for veteran residents.

\section{CONCLUSIONS}

Water shortage and environmental damage are not necessarily caused by population size and do not necessarily constitute a valid argument in favor of small quotas of immigration to a continent that is the second remotest and least populated one, that has a low rate of human fertility, aging population and shortage of skilled labor, and that is one of the preferred destination for skillful immigrants. The persistently large urban-agricultural price differential and the system of water rights have perpetuated inefficient allocation and wasteful use of water and land resources in that continent. A diversion of fresh water rights from farmers to the more easily and better coordinated and monitored urban users can support a much larger population and may improve the overall management of that continent's land and water resources. Considering that a large, fast population growth is only

Table 1. Optimal Population Size, Urban Share, Expected Net Benefit and Unemployment for Various Agricultural Water Prices

\begin{tabular}{|c|c|c|c|c|c|c|}
\hline $\begin{array}{l}\text { Agricultural Water Price (\$) } \\
\text { Urban Water Price (\$) }\end{array}$ & $\begin{array}{l}\mathbf{0 . 0 7} \\
\mathbf{2 . 0 7}\end{array}$ & $\begin{array}{c}0.014 \\
2.07\end{array}$ & $\begin{array}{l}\mathbf{0 . 3 0} \\
\mathbf{2 . 0 7}\end{array}$ & $\begin{array}{l}\mathbf{0 . 4 0} \\
2.07\end{array}$ & $\begin{array}{l}\mathbf{0 . 8 0} \\
\mathbf{2 . 0 7}\end{array}$ & $\begin{array}{l}1.25 \\
2.07\end{array}$ \\
\hline $\begin{array}{l}\text { Scenario A } \\
\text { Population (millions) } \\
\text { Urban population share } \\
\text { Expected net benefit for urban workers and farmers (\$) } \\
\text { Urban unemployment rate }\end{array}$ & $\begin{array}{c}20 \\
0.968 \\
40,356 \\
0.05\end{array}$ & $\begin{array}{c}26 \\
0.975 \\
40,609 \\
0.05\end{array}$ & $\begin{array}{c}32 \\
0.981 \\
40,562 \\
0.05\end{array}$ & $\begin{array}{c}36 \\
0.984 \\
40,455 \\
0.05\end{array}$ & $\begin{array}{c}38 \\
0.989 \\
40.349 \\
0.05\end{array}$ & $\begin{array}{c}48 \\
0.995 \\
39,915 \\
0.05\end{array}$ \\
\hline $\begin{array}{l}\text { Scenario B } \\
\text { Population (millions) } \\
\text { Urban population share } \\
\text { Expected net benefit for urban workers and farmers }(\$) \\
\text { Urban unemployment rate }\end{array}$ & $\begin{array}{c}20 \\
0.968 \\
40,356 \\
0.05\end{array}$ & $\begin{array}{c}27 \\
0.976 \\
41,610 \\
0.04\end{array}$ & $\begin{array}{c}38 \\
0.984 \\
42,049 \\
0.03\end{array}$ & $\begin{array}{c}44 \\
0.987 \\
42,029 \\
0.02\end{array}$ & $\begin{array}{c}46 \\
0.991 \\
41,969 \\
0.02\end{array}$ & $\begin{array}{c}47 \\
0.995 \\
41,915 \\
0.02\end{array}$ \\
\hline $\begin{array}{l}\text { Scenario C } \\
\text { Population (millions) } \\
\text { Urban population share } \\
\text { Expected net benefit for urban workers and farmers }(\$) \\
\text { Urban unemployment rate }\end{array}$ & $\begin{array}{c}20 \\
0.968 \\
40,356 \\
0.05\end{array}$ & $\begin{array}{c}14 \\
0.961 \\
40,612 \\
0.03\end{array}$ & $\begin{array}{c}23 \\
0.975 \\
40,231 \\
0.06\end{array}$ & $\begin{array}{c}20 \\
0.974 \\
40,535 \\
0.05\end{array}$ & $\begin{array}{c}17 \\
0.979 \\
40,620 \\
0.04\end{array}$ & $\begin{array}{c}19 \\
0.989 \\
40,468 \\
0.05\end{array}$ \\
\hline
\end{tabular}


achievable through massive immigration, the paper attempted to model and to simulate the aggregate impact of a large intake of skilful immigrants on the continent's social and cultural cohesion, economy and degree of isolation.

A socioeconomic model comprising rural and urban sectors was constructed. In addition to the effect on expected incomes, the construction took into account the effects of immigration fueled population growth on the island's levels of isolation, social cohesion and employment and on the island's environment. Free internal flows of human, water and land resources between the sectors that exhaust any difference between the sectors' per capita expected net benefits were allowed. The model identified the population size and its urban-rural distribution that maximize the per capita expected net benefit. The numerical simulations of the model revealed the critical role of urban employment prospects in assessing the carrying capacity and the efficient use of land and water resources in the habitable ten-percent area of a distant, large, arid island similar to Australia. As argued in the introduction, newcomers tend to reside in Australia's urban centers. If, in these centers, the immigration induced rise in the labor supply exceeds the rise in the labor demand generated by the increased demand for goods, then, in agreement with the advocates of a slow population growth, a large intake of immigrants would lower per capita expected net benefit and hence might not serve the interest of the veteran residents. However, if the probability of employment in the urban centers is not hindered by fast population growth, a policy that reduces the urban-rural water-price differential and allows large intakes of skillful immigrants may double the island's population without a loss of expected net benefit for its veteran residents.

\section{REFERENCES}

[1] Betts K. Sydney and the bush: no growth and some hope. Migration Action 1990; 12(3): 21-24.

[2] Goldie J. Population-environmental impact of population growth. Population 2002; 58: 8-13.

[3] Barney F, Franzi P. Future Dilemmas: Options to 2050 for Australia's Population, Technology, Resources and Environment. Report to the Department of Immigration and Multicultural and Indigenous Affairs by CSIRO Sustainable Ecosystems Division, CSIRO Resource Futures. Working paper series 2002/01.

[4] Burnley IH. Immigration, population and urban growth in Australia. Migration Action 1990; 12(3): 3-6.

[5] Clarke H. Should Australia target its population size? Econ Pap 2003; 22(1): 24-35.

[6] Schultz TW. Reflection on investment in man. J Polit Economy 1962; 70: 1-9.

[7] Sjaastad LA. The costs and returns of human migration. J Polit Economy 1962; 70: 80-93.

[8] Todaro MP. A model of labor migration and urban unemployment in less developed countries. Amer Econ Rev 1969; 59: 138-48. 